\title{
Sleep-Wake Pattern, Sleep Quality and Daytime Status in Fixed Day-Shift Hospital Workers
}

\author{
Su Jung Choi ${ }^{1}$, Hyunjin $\mathrm{Jo}^{2}$, Dongyeop Kim ${ }^{2 *}$, Eun Yeon Joo ${ }^{2}$ \\ ${ }^{1}$ Graduate School of Clinical Nursing Science, Sungkyunkwan University, Seoul, \\ ${ }^{2}$ Department of Neurology, Neuroscience Center, Samsung Medical Center, Sungkyunkwan University School of Medicine, Seoul, Korea
}

\author{
상근직 병원 근로자의 수면과 주간기능 실태조사 \\ 최수정 ${ }^{1}$, 조현진 ${ }^{2}$, 김동엽 ${ }^{2 *}$, 주은연 ${ }^{2}$ \\ ${ }^{1}$ 성균관대학교 임상간호대학원, ${ }^{2}$ 성균관대학교 의과대학 삼성서울병원 신경과, 뇌신경센터
}

$\begin{array}{ll}\text { Received } & \text { October 25, 2021 } \\ \text { Revised } & \text { December 2, } 2021 \\ \text { Accepted } & \text { December 15, 202 }\end{array}$

Address for correspondence Eun Yeon Joo, MD, PhD

Department of Neurology, Neuroscience Center,

Samsung Medical Center,

Sungkyunkwan University

School of Medicine,

81 Irwon-ro, Gangnam-gu,

Seoul 06351, Korea

Tel: $+82-2-3410-3599$

Fax: +82-2-3410-0052

E-mail: eunyeon.joo@gmail.com

*Current affiliation: Department of Neurology, Ewha Womans

University Seoul Hospital, Ewha

Womans University College of

Medicine, Seoul, Korea
Objectives: Sleep issues are more prevalent in healthcare workers compared to workers in other industries. This study investigated sleep-wake pattern, sleep quality, and daytime status in hospital workers using a Galaxy Watch3 (GW3), a wrist-worn device that uses an accelerometer and heart rate sensor to distinguish sleep and wakefulness. Methods: Multiple sleep parameters including total sleep time (TST) were obtained using a GW3. The Epworth sleepiness scale (ESS), insomnia severity index (ISI), Pittsburgh sleep quality index (PSQI), and bedtime procrastination scale (BPS) were used to assess participants' status. Results: A total of 70 daytime hospital workers (male, $45.7 \%$; mean age, $35.66 \pm 7.79 \mathrm{yr}$ ) participated in the monitoring of their sleep-wake patterns for 30 consecutive days. Participants had a mean ESS of 8.14 \pm 3.62 , ISI of $6.13 \pm 3.83$, and PSQI of $4.86 \pm 2.14$. The mean TST was $5.75 \pm 0.74 \mathrm{hr}$ (range: $3.42-6.88$ ) during workdays and 5.92 $\pm 0.92 \mathrm{hr}$ (range: $2.87-8.25$ ) during free days. Chronotype (mid-sleep on freedays corrected for sleep debt accumulated over the work week) was $3.60 \pm 1.03$ clock $\mathrm{hr}$ (range: 1.84-6.69). BPS was negatively correlated with age ( $r h o=-0.27, p=0.022$ ), TST of workdays (rho $=-0.53, p<0.001$ ), and TST of free days (rho $=-0.43, p<0.001)$. A higher BPS was associated with larger social jetlag (rho=0.28, $p=0.018$ ) and later chronotype (rho=0.41, $p<0.001$ ). Conclusions: In this study, $91.5 \%$ of daytime hospital workers suffered from chronic sleep insufficiency ( $<7 \mathrm{hr}$ during both workdays and free days) although their daytime sleepiness or subjective sleep were not poor. Individuals with a later chronotype had poorer sleep quality and worse sleep procrastination behavior.

J Sleep Med 2021;18(3):167-174

Keywords: Wearable electronic devices; Sleep; Circadian rhythm; Health personnel.

\section{서 론}

수면은 휴식과 안정을 제공하여 신체적, 정신적 항상성을 유지하는데 필수적이나, 현대인들은 여러가지 이유로 양적 으로나 질적으로 좋은 수면을 취하기 어려운 경우가 많다. 수면에 문제가 생기면 집중력이 감소하고 인지 및 정신운동 수행에 부정적 영향을 주어, 사고, 손상 등을 유발하여 생산 성을 떨어뜨릴 수 있다. ${ }^{1}$ 특히 병원 근로자들은 환자들을 상

This is an Open Access article distributed under the terms of the Creative Commons Attribution Non-Commercial License (https://creativecommons.org/licenses/by-nc/4.0) which permits unrestricted non-commercial use, distribution, and reproduction in any medium, provided the original work is properly cited.
대해야 하므로 개인의 수면은 단순히 개인적 건강의 문제를 넘어서는 이차적 문제를 초래할 수 있으므로 적절한 수면은 매우 중요하다.

지금까지 병원 근로자들의 수면에 관한 연구들은 대부분 교대근무자에 집중되어 있어서, 주로 교대근무 간호사를 대 상으로 한 연구들이 대부분이다. ${ }^{2-5}$ 교대근무자들이 상근자 들보다 수면장애가 더 많다고 보고되고 있지만, 6,7 병원 근로 자들의 $56.9 \%$ 가 7-8시간 정도의 적정 수면을 취하지 못한다 는 보고도 있음을 고려하면 ${ }^{8}$ 행정직을 비롯한 상근자들의 수 면에 대해서도 조사해 볼 필요가 있다. 특히 평소 일생생활 하에서 근무일과 휴일의 수면은 차이가 있는지, 수면과 관련 
된 습관이나 주관적으로 인지하는 수면과 관련된 어려움이 있는지 확인이 가능하다면 수면을 개선할 수 있는 중재나 교육도 적용해 볼 수 있을 것이다.

개인의 수면을 조사하는 방법은 수면다원검사와 같은 객 관적이고 표준적인 방법이 있지만, 수면다원검사는 수면호 흡장애나 수면과다증이 의심되는 경우에만 보험급여 적용이 되어, 그렇지 않은 경우는 고가의 검사비를 지불해야 한다. 무엇보다, 이는 하룻밤의 검사이므로 일상생활에서의 수면각성주기를 확인할 수 없는 제한점이 있다. 이에 수면을 중 장기적으로 기록할 수 있는 여러 웨어러블 기기들이 개발되 었고, 그 중 스마트폰과 연동되는 스마트워치들은 내장된 가 속도센서(accelerometers)와 광용적맥파(photoplethysmogram) 센서로 움직임과 혈류 변화를 측정하여 수면-각성상 태 및 수면시간, 수면단계, 수면 중 깸 횟수도 제공한다. 스마 트워치는 스마트폰과 연동이 되므로 착용기간 동안 사용자 가 쉽게 자신의 수면상태를 확인할 수 있고, 기기 충전도 용 이하여 장시간 착용하더라도 방전의 위험성이 적어 보다 용 이하게 수면을 측정할 수 있는 장점이 있으며, 수면-각성 분 류 정확도를 $90 \%$ 까지 보고한 연구도 있다. ${ }^{9}$ 갤럭시워치로 측 정된 수면지표에 대한 타당도 연구 보고는 아직 없지만, 갤 럭시워치도 애플워치와 마찬가지로 가속도센서와 광센서가 내장되어 있어 애플워치 기반 선행연구 ${ }^{9}$ 와 유사한 일치율을 보인다는 가정하에 국내에서 시장점유율이 높은 삼성폰과 연동되는 갤럭시워치에서 얻은 수면자료로 성인들의 수면 실태를 조사해 볼 필요가 있다.

본 연구에서는 대학병원의 상근직 근로자를 대상으로 갤 럭시워치를 이용하여 4주간 평상시 측정한 수면-각성주기 및 수면시간을 측정하고, 이들의 주간 상태와 야간 수면의 질을 주관적으로 평가하는 설문지를 시행했다. 본 연구의 가 설은, 병원의 상근직 근로자의 수면시간이 짧을수록 수면의 질이 떨어져 주간활동에 지장을 초래할 것으로 세웠다.

\section{방 법}

\section{대 상}

본 연구의 대상자는 서울소재 단일 상급종합병원에서 일 하는 직원을 대상으로 공고문을 통해 자발적으로 참여를 희 망한 자를 모집하였다. 선정기준은 1) 연구목적을 이해하고 동의한 만 20세 이상 60세 미만인 자; 2) Galaxy Watch3 (GW3)를 소유하고 상용하는 자로 하였다. 제외 기준은 1) 교 대근무자; 2) 불안정하거나 심각한 내과적, 정신과적 질환; 3) 심한 코골이, 기면증, 렘수면 장애가 있는 자이다.

본 연구에서 사용된 연구 기준, 방법 및 평가는 삼성서울
병원 기관윤리심의위원회의 심의(승인번호 2021-09-130)를 받고, 기관윤리심의위원회의 관리감독하에 시행되었다.

\section{연구방법 및 척도}

대상자 모집 및 자료수집을 위해 연구대상 병원기관 윤리 심의위원회(IRB)의 승인(승인번호 2021-09-130)을 얻은 후 연구 목적을 설명하고 자발적 동의를 구한 후 시행하였다. 연구참여에 동의 후 자가보고형 설문지를 작성하였고, 연구 에 참여하는 4주동안 매일 취침 전에 $\mathrm{GW}$ 를 착용하고 잠자 리에 들어가도록 하였고, 기상 후 연동되는 스마트폰에 기록 된 수면결과를 캡처해서 카카오톡을 이용해서 보내주도록 하였다.

\section{스마트워치}

본 연구에서는 스마트워치 GW3 (Samsung Electronics, Seoul, Korea)를 이용했다. GW3는 비우세 손목에 시계처럼 착용하면 손목에서 감지되는 움직임과 심박수 등의 생체신 호를 측정하여 제조사의 알고리즘에 따라 수면-각성 및 수 면단계를 자동으로 계산하여 GW3 및 연동되는 스마트폰에 수면결과지표를 제시한다. GW3에서 측정되는 수면지표는 수면 시작 시각(sleep onset, SO), 수면 종료 시각(sleep end, $\mathrm{SE}$ ), 총 수면시간(total sleep time, TST), 입면 후 각성시간 (wakefulness after sleep onset [WASO], \%), 얕은 수면(light sleep, \%), 깊은 수면(deep sleep, \%), 렘수면(rapid eye movement [REM] sleep, \%), 및 수면 점수(sleep score)가 있다.

본 연구에서는 총 4주간 매일 수면 결과를 받아서 다시 근 무일(workdays, W)과 휴일(freedays, F)로 나누어 각각의 평 균 값을 구하였고, 근무일과 휴일간의 수면의 차이를 확인하 기 위해 사회적 시차(social jetlag, SJL)와 시간 기반 일주기 유형은 교정된 휴일 중간수면(mid-sleep time on free days corrected for sleep debt accumulated over the work week, $\mathrm{MSFsc}$ )을 계산하였다. SJL과 MSFsc는 개인의 일주기유형 을 측정하기 위해 사용한 Munich chronotype questionnaire (MCTQ) 도구의 계산방법을 이용하여 산출하였다. ${ }^{10}$ 수면기 간(sleep duration, $\mathrm{SD}$ )은 수면 종료 시각에서 수면 시작 시각 을 뺀 값으로 계산하고 $(\mathrm{SD}=\mathrm{SE}-\mathrm{SO})$, 중간수면시간(mid-sleep, $\mathrm{MS})$ 은 $\mathrm{SO}+\mathrm{SD} / 2$ 로 계산하였고, 생물학적 시계와 사회적 시계 사이의 불일치인 사회적 시차는 휴일의 중간수면(mid-sleep time on freedays, MSF)과 근무일의 중간수면(mid-sleep time on workdays, MSW)의 차이로 계산하였다(SJL=MSF$\mathrm{MSW}$ ). MSFsc는 다음과 같은 공식으로 계산하였다.

If $\mathrm{SD}_{\mathrm{F}}$ (SD on freedays) $\leq \mathrm{SDw}$ (SD on weekdays), $\mathrm{MSF}_{\mathrm{SC}}=$ MSF 
If $\mathrm{SD}_{\mathrm{F}}>\mathrm{SDw}, \mathrm{MSF}_{\mathrm{SC}}=\mathrm{MSF}-\left(\mathrm{SD}_{\mathrm{F}}-\right.$ average weekly $\left.\mathrm{SD}\right) / 2$

\section{설문지}

대상자는 다음과 같은 자가보고형 설문지를 작성하였다. 불면증 심각도 정도는 7문항의 한글판 불면증 심각도 지수 (insomnia severity index, ISI), ${ }^{11}$ 낮시간 동안의 졸림을 평가 하는 8문항의 엡워스 주간졸림증 척도(Epworth sleep scale, $\mathrm{ESS}){ }^{12}$ 주관적 수면의 질을 평가하는 19 문항의 피츠버그 수 면의 질 척도(Pittsburgh sleep quality index-Korean, PSQI$\mathrm{K}),{ }^{13}$ 9문항의 피로도 척도(fatigue severity scale, FSS) ${ }^{14}$ 스 트레스에 대한 불면의 취약성을 평가하기 위한 9문항의 스트 레스 불면 반응 설문(Ford insomnia response to stress test, FIRST), ${ }^{15}$ 그리고 외부적인 요인이 없음에도 계획했던 것보 다 잠자리에 늦게 들어가는 행동의 정도를 측정하는 9 문항의 취침시간 지연행동 척도(bedtime procrastination scale, $\mathrm{BPS})^{16}$ 를 작성하였다. ISI는 점수가 높을수록 불면증 심각도가 높으 며, ESS 점수가 높을수록 주간 졸림의 정도가 크며, PSQI는 점수가 높을수록 수면의 질이 떨어지고, FSS는 점수가 높을 수록 피로가 심하며, FIRST 점수가 높을수록 스트레스와 관 련된 불면의 취약성이 큼을, BPS는 점수가 높을수록 취침시 간 지연행동이 많음을 의미한다.

\section{자료분석 방법}

수집된 자료는 유의수준 0.05 로 하여 윈도우용 SPSS 20.0 (IBM Corp., Armonk, NY, USA)을 이용하여 다음과 같이 분석하였다. 대상자의 일반적 특성, 설문 점수 및 수면 패턴 은 빈도와 백분율, 평균과 표준편차를 이용하였다. 측정 변수 들과 수면 패턴간 상관관계는 Spearman correlation을 이용 하여 분석하였다. 또한 대상자의 직군별 일반적 특성, 설문 점수 및 수면 패턴간의 차이는 Kruskal-Wallis test를 이용하 여 분석하였다.

\section{결 과}

\section{일반적 특성 및 설문 점수}

전체 참여 대상자는 70명이었으며, 대상자의 평균 연령은 $35.66 \pm 7.79$ 세(range: 20-51세)였고, 남성이 45.7\%(32명)였 고, $57.1 \%$ (40명)가 기혼자였다. 근로자의 직군은 행정직이 $31.4 \%$ 로 가장 많았고, 의료기사직이 $27.1 \%$, 연구 코디네이터 가 $24.3 \%$, 간호사가 $10.0 \%$, 의사가 $7.2 \%$ 순이었다. 대상자의 $80.0 \%$ 가 카페인 음료를 마시고, $75.7 \%$ 가 비흡연자인 것으로

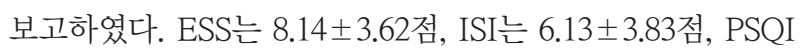
는 $4.86 \pm 2.14$ 점, FSS는 $28.47 \pm 9.38$ 점, FIRST는 18.54 \pm
6.73점이었다(Table 1).

\section{수면의 질과 수면-각성주기}

근무일의 평균 수면 시작 시각(SO)은 $23.85 \pm 0.96$ 시이고, 수면 종료 시각(SE)은 $6.48 \pm 0.64$ 시였고, 수면 기간은 $6.63 \pm$ 0.88 시간, $\mathrm{WASO}$ 는 $12.60 \pm 3.60 \%$, TST는 $5.75 \pm 0.74$ 시간으 로 모두 7시간 미만의 수면을 취하고 있었다. 휴일의 $\mathrm{SO}$ 와

Table 1. Demographic characteristics and sleep-related questionnaires $(n=70)$

\begin{tabular}{cc}
\hline Characteristics & Value \\
\hline Age $y r$ & $35.66 \pm 7.79(20-51)$
\end{tabular}

Sex

Male

$32(45.7)$

Marital status

Single

29 (41.4)

Married

40 (57.1)

Divorced

1 (1.4)

Education

High school

7 (10.0)

Bachelor

38 (54.3)

Postgraduate

23 (32.9)

Being in college

2 (2.9)

Job

Medical doctor

5 (7.2)

Nurse

7 (10.0)

Technician

19 (27.1)

Administrator

22 (31.4)

Research coordinator

17 (24.3)

Caffeine use

$56(80.0)$

Drinking

49 (70.0)

Smoking

Non-smoker

53 (75.7)

Ex-smoker

$10(14.3)$

Smoker

7 (10.0)

BMI, kg/m²

ESS

$23.60 \pm 3.25(16.9-34.0)$

ISI

$8.14 \pm 3.62(2-19)$

ISI

$6.13 \pm 3.83(0-15)$

PSQI

$4.86 \pm 2.14(1-10)$

FSS

$28.47 \pm 9.38(12-57)$

FIRST

$18.54 \pm 6.73(9-34)$

BPS

$22.21 \pm 7.33(9-38)$

Data are presented as mean \pm standard deviation (range) or $\mathrm{n}(\%)$. BMI, body mass index; ESS, Epworth sleepiness scale; ISI, insomnia severity index; PSQI, Pittsburgh sleep quality index; FSS, fatigue severity scale; FIRST, Ford insomnia response to stress test; BPS, bedtime procrastination scale 
$\mathrm{SE}$ 는 $0.31 \pm 1.25$ 시와 $7.18 \pm 1.00$ 시로 근무일보다는 좀 더 뒤 로 지연되는 경향을 보였다. 휴일의 TST는 $5.92 \pm 0.92$ 시간으 로, 6시간 이상 7시간 미만인 경우가 $45.7 \%$ 로 가장 많이 분 포하였다. REM sleep \%와 deep sleep \%는 근무일에는 각각 $24.52 \pm 2.71 \%, 6.30 \pm 3.19 \%$ 였고, 휴일은 $23.97 \pm 3.51 \%, 6.01 \pm$ 3.45 였다. 사회적 시차는 평균 $0.58 \pm 0.62$ 시간이었고, 일주기

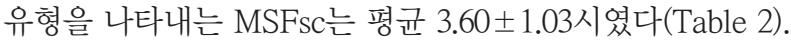

Table 2. Sleep parameters by GW3 for 4 weeks $(n=70)$

\begin{tabular}{|c|c|}
\hline Variables & Value \\
\hline \multicolumn{2}{|l|}{ Workdays } \\
\hline Sleep score & $62.33 \pm 10.64(45-92)$ \\
\hline Sleep onset, clock hr & $23.85 \pm 0.96(22.20-2.37)$ \\
\hline Sleep end, clock hr & $6.48 \pm 0.64(4.92-8.33)$ \\
\hline Sleep duration, $\mathrm{hr}$ & $6.63 \pm 0.88(3.88-8.25)$ \\
\hline WASO, \% & $12.60 \pm 3.60(6.80-22.71)$ \\
\hline TST, hr & $5.75 \pm 0.74(3.42-6.88)$ \\
\hline$<5$ & $11(15.7)$ \\
\hline$\geq 5$ to $<6$ & $30(42.9)$ \\
\hline$\geq 6$ to $<7$ & $29(41.4)$ \\
\hline REM sleep, \% & $24.52 \pm 2.71(14.57-30.36)$ \\
\hline Light sleep, \% & $69.79 \pm 4.54(57.65-78.93)$ \\
\hline Deep sleep, \% & $6.30 \pm 3.19(1.60-17.54)$ \\
\hline \multicolumn{2}{|l|}{ Freedays } \\
\hline Sleep score & $60.79 \pm 11.04(43-93)$ \\
\hline Sleep onset, clock hr & $0.31 \pm 1.25(22.13-3.92)$ \\
\hline Sleep end, clock hr & $7.18 \pm 1.00(5.02-10.95)$ \\
\hline Sleep duration, hr & $6.87 \pm 1.03(3.63-9.03)$ \\
\hline WASO, \% & $13.63 \pm 3.90(6.33-24.08)$ \\
\hline TST, hr & $5.92 \pm 0.92(2.87-8.25)$ \\
\hline$<5$ & $9(12.9)$ \\
\hline$\geq 5$ to $<6$ & $23(32.8)$ \\
\hline$\geq 6$ to $<7$ & $32(45.7)$ \\
\hline$\geq 7$ & $6(8.6)$ \\
\hline REM sleep, \% & $23.97 \pm 3.51(13.89-32.32)$ \\
\hline Light sleep, \% & $70.89 \pm 5.04(59.90-81.77)$ \\
\hline Deep sleep, \% & $6.01 \pm 3.45(0.57-19.33)$ \\
\hline Social jetlag, hr & $0.58 \pm 0.62(-0.69-3.22)$ \\
\hline \multicolumn{2}{|l|}{ Midsleep } \\
\hline MSW, clock hr & $3.17 \pm 0.69(1.58-5.14)$ \\
\hline MSF, clock hr & $3.74 \pm 1.01(2.20-6.81)$ \\
\hline MSFsc, clock hr & $3.60 \pm 1.03(1.84-6.69)$ \\
\hline
\end{tabular}

Data are presented as mean \pm standard deviation (range) or $\mathrm{n}(\%)$. GW3, Gallaxy Watch3; WASO, wakefulness after sleep onset; TST, total sleep time; MSW, mid-sleep time on workdays; MSF, midsleep time on freedays; MSFsc, mid-sleep time on freedays corrected for sleep debt accumulated over the work week
사회적 시차는 0-0.5시간이 $40 \%$ 로 가장 많았으며, MSFsc로 조사된 chronotype 분포는 2.5 시 이상-3.5시 미만 시간대에 $34.2 \%$ 로 가장 많이 분포하는 것으로 나타났다(Fig. 1).

\section{수면 패턴과 주관적 설문지와의 상관관계}

상관분석 결과 나이가 적을수록 $\mathrm{ESS}, \mathrm{FSS}, \mathrm{BPS}$ 점수가 높았으며, 여성이 남성보다 FIRST 점수가 높았다. 근무일의 잠드는 시각이 늦을수록 PSQI와 BPS 점수가 높았고, 휴일 의 잠드는 시각이 늦을수록 나이가 적고, ISI, PSQI, BPS 점 수가 높았다. 근무일의 TST가 낮을수록 PSQI와 BPS 점수가 높았으며, 휴일의 TST가 낮을수록 ISI, PSQI, BPS 점수가 높았다. 수면 단계 중 근무일과 휴일의 REM sleep \%와 BPS 점수가 역상관관계를 보였고, light sleep이나 deep sleep \%와 는 유의한 상관관계를 보이지 않았다. 사회적 시차가 클수록 FSS와 BPS 점수가 높았다. Chronotype이 지연될수록 나이가 적고, PSQI와 BPS 점수가 높은 것으로 조사되었다(Table 3).

\section{직군별 일반적 특성, 설문 점수 및 수면 패턴 비교}

일반적 특성 중 근무시간(식사시간 포함)이 의사직이 11.10 시간으로 가장 길고, 행정직이 9.03시간으로 가장 짧아 직군간 유의한 차이를 보였다 $(p<0.001)$. 설문 점수는 ISI와 $\mathrm{PSQI}$ 점수가 유의한 차이를 보였는데, ISI는 행정직과 연구 직이 높은 점수를 보였고( $p=0.014), \mathrm{PSQI}$ 는 연구직이 6.00점 으로 가장 높고, 간호직이 5.29점으로 두번째로 높은 점수를 보였다 $(p=0.035)$. 수면 패턴은 근무일의 수면은 직군간 차이 를 보이지 않았고, 휴일의 $\mathrm{SO}, \mathrm{SE}, \mathrm{MSF}$ 가 유의한 차이를 보 였고, MSFsc도 유의한 차이를 보여 의사직이 4.57시로 가장 지연되는 것으로 조사되었다 $(p=0.035)$ (Table 4).

\section{고 찰}

본 연구는 상근직 병원 근로자들을 대상으로 웨어러블 디 바이스(GW3)를 통해 4주간 일상생활을 유지하면서 측정된 수면 자료와 수면관련 설문지간의 상관관계를 확인하였다. 애플워치와 수면다원검사 간의 수면을 비교한 다른 연구에 서 수면-각성 분류 정확도는 $90 \%$ 로 높다는 선행연구 ${ }^{9}$ 에 기 반하여 건강한 주간 상근직 직장인의 일상생활에서의 수면 패턴을 확인하고자 했다.

본 연구대상자인 상근 보건직 근로자들의 잠드는 시각은 근무일의 경우 평균 23.85시, 휴일에는 0.31시였고, TST는 근 무일에는 평균 5.75시간으로 모든 대상자의 수면시간이 7시 간 미만이었고, 휴일에도 평균 5.92시간이었다. 고로, 주중주말을 합한 평균 수면시간이 7시간 미만인 경우는 91.5\%인 

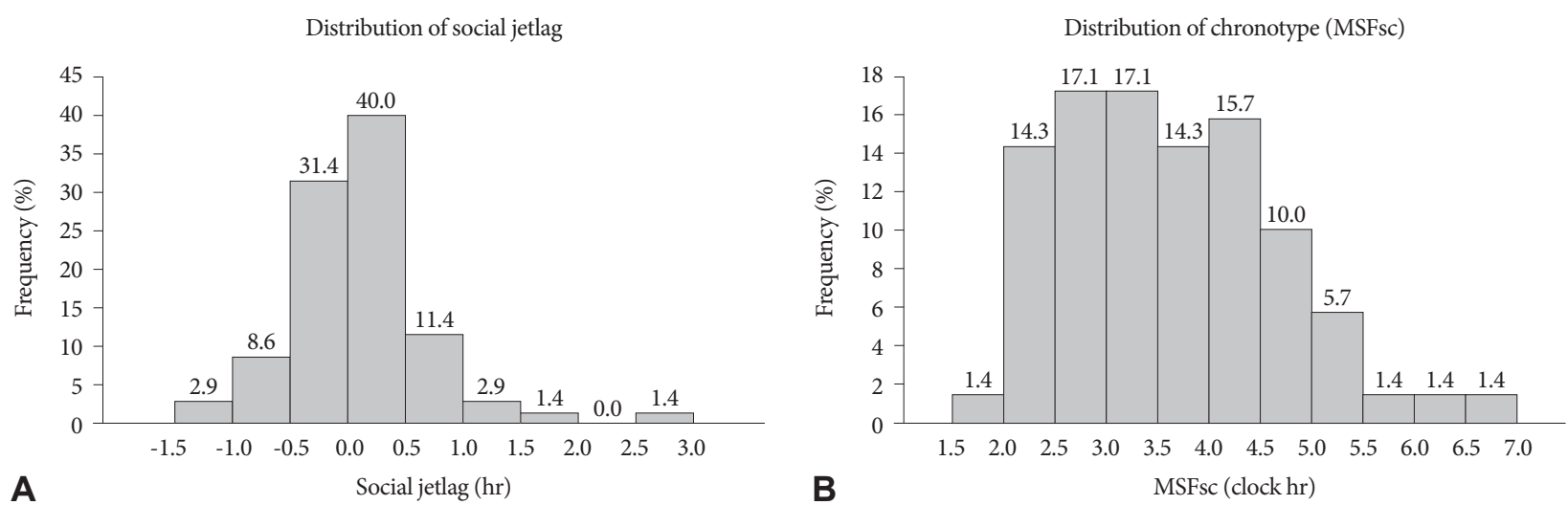

Figure 1. Distribution of social jetlag (A) and chronotype (B). MSFsc, mid-sleep time on free days corrected for sleep debt accumulated over the work week.

것으로 나타났다. 인구통계조사인 국민건강영양조사 제 7기 수면 실태조사에 따르면 19세 이상 성인의 하루 평균 수면시 간은 주중은 7.0시간, 주말은 7.7시간으로 보고된 것 ${ }^{17}$ 과 비교 하면 본 상근 병원 보건직근로자의 수면시간이 1 시간 이상 적은 것이다. 근무일과 휴일의 TST가 적을수록 주관적 수면 의 질이 떨어지고, 취침시간 지연행동 관련 점수도 더 높았 다. 취침시간 지연행동(BPS) 점수가 높을 수록, 나이는 젊고, 근무일과 휴일의 수면시작시각이 늦었으며, 수면 중 REM sleep \%가 낮고, TST가 짧으며, 사회적 시차가 컸고, 일주기 유형이 지연성인 것으로 나타났다. 취침시간 지연행동 점수 가 높은 사람들은, 스마트폰 시청과 같은 취침 전 전자기기 사용시간이 더 많은 것을 고려하면 ${ }^{18}$ 취침시간 지연행동으로 인한 취침 전 빛 노출 증가가 잠드는 시각을 더 늦추고 수면 의 질을 더 떨어뜨릴 것으로 예상할 수 있다. 또한 스마트폰 중독은 취침시간 지연행동을 증가시킬뿐만 아니라 우울과 불안과 같은 부정적 감정을 유발할거나 악화시킬 수 있다. ${ }^{19}$ 따라서 본 피험자들에게 수면건강뿐만 아니라, 정신건강의 향상을 위하여 취침시간 지연행동을 줄이는 적극적인 중재 개입이 필요하겠다.

본 피험자들의 사회적 시차는 평균 1 시간 미만으로(범위 $-0.69-3.22$ 시간) $97.2 \%$ 가 2시간 미만인 것으로 관찰되었다. 이는 유럽에서 시행한 대규모 인구조사에서 상근자의 사회 적 시차는 1 시간 이하가 $38.8 \%, 1$-2시간이 $29.1 \%$ 였으며 ${ }^{20}$ 본 피험자들의 사회적 시차는 더 작았다. 사회적 시차는 개인의 생체시계(biological clock)와 사회적 시계(social clock)간의 만성적인 불일치 정도로 일주기리듬의 어긋남(circadian misalignment)인데, ${ }^{21}$ 본 연구 대상자의 일주기리듬불일치는 예 상보다는 크지 않았다. 주중 수면이 부족한 경우 수면부족 (sleep debt)을 보충하기 위해 휴일에 잠을 보충하느라 사회 적 시차가 발생하며,22 이러한 회복 수면(catch-up sleep)이 건강에 긍정적인 영향을 준다는 연구도 있지만, ${ }^{23}$ 오히려 일
주기를 더 지연시키거나 월요병을 유발할 수 있다..$^{20}$ 본 피험 자들이 근무일에도 7시간 미만으로 수면부족이 예상되므로 휴일에 부족한 수면을 보상하기 위한 회복 수면이 좀 더 필 요할 것으로 생각되나 휴일에도 수면시간이 그다지 증가하 지 않아, 만성적인 수면부족일 가능성이 있다. 다만, 휴일 낮 시간 동안의 수면 여부를 조사하지 않아서 해석에 제한점이 있을 수 있다. 병원근로자의 수면에 대한 연구들이 대부분 교대근무 간호사에 집중되어 있어 상근근로자의 연구를 직 접 비교하기는 어려우나, 2004년 교대간호사와 상근근로자 를 포함한 병원 근로자들의 $56.9 \%$ 가 일 7-8시간의 충분한 수면을 취하지 못한다고 보고한 조사를 고려한다면, ${ }^{8}$ 병원 근로자의 수면시간은 과거에 비해 현저하게 줄어든 것을 알 수 있다. 특히 보건직 근로자의 수면부족은 의료기간 내 안 전사고 위험을 높여서 환자들의 안전도 위협할 수 있는 중 대한 문제이다. ${ }^{1}$ 다만, 본 연구에 응한 피험자들은 주간졸음 (ESS)이나 야간 불면증(ISI)을 거의 호소하지 않고 주관적인 수면의 질(PSQI)도 그리 나쁘지 않게 평가했다. 짧은 수면시 간임에도 불구하고 주간기능의 장애를 경험하지 않는 것으 로 보고하였는데, 이는 대상자의 평균 연령이 35.6세로 젊고, 사회적 시차가 없기 때문이 아닌가 추정되나 본 연구 대상자 수가 적어 일반화하기에는 제한이 있다. 하지만, 향후 지속적 인 수면부족으로 인한 폐해는 발생할 수 있으므로, 근로자의 수면 개선을 위한 수면 방해 요인을 파악하고 이를 해결하기 위한 적극적 노력이 필요하겠다.

본 연구 대상자의 나이가 적을수록 사회적 시차가 크고 일 주기유형도 늦어지는 것으로 나타났다. 이는 주관적 설문지 인 $\mathrm{MCTQ}$ 로 일주기유형을 조사한 미국의 대규모 인구조사 연구에서 10 세부터 20 세까지는 나이가 많아질수록 일주기 유형이 지연되다가 20세 이후부터는 점차 일주기유형이 앞 으로 당겨진다는 연구와 유사한 결과를 보였다. ${ }^{24}$ 또한 본 연 구에서 저녁형 일주기유형일수록 주관적 수면의 질이 낮았 
Table 3. Spearman correlation between sleep parameters and questionnaires $(n=70)$

\begin{tabular}{|c|c|c|c|c|c|c|c|c|}
\hline & Age & Male (sex) & ESS & ISI & PSQI & FSS & FIRST & BPS \\
\hline \multirow[t]{2}{*}{ Age } & 1 & & $-0.289^{*}$ & -0.161 & -0.146 & $-0.236^{*}$ & 0.115 & $-0.273^{*}$ \\
\hline & & & $(0.015)$ & $(0.183)$ & $(0.229)$ & $(0.049)$ & $(0.342)$ & $(0.022)$ \\
\hline \multirow[t]{2}{*}{ Male (sex) } & 0.050 & 1 & -0.160 & 0.087 & -0.029 & -0.118 & $-0.343^{*}$ & -0.024 \\
\hline & $(0.683)$ & & $(0.187)$ & $(0.474)$ & $(0.813)$ & $(0.331)$ & $(0.004)$ & $(0.843)$ \\
\hline \multirow[t]{2}{*}{$\mathrm{SO}_{\mathrm{W}}$} & -0.217 & 0.104 & 0.181 & 0.159 & $0.427^{*}$ & 0.017 & -0.222 & $0.498^{*}$ \\
\hline & $(0.071)$ & $(0.390)$ & $(0.134)$ & $(0.188)$ & $(<0.001)$ & $(0.889)$ & $(0.065)$ & $(<0.001)$ \\
\hline \multirow[t]{2}{*}{$\mathrm{REMS}_{\mathrm{W}}$} & 0.068 & -0.180 & 0.021 & -0.105 & -0.110 & -0.132 & 0.061 & $-0.273^{*}$ \\
\hline & $(0.576)$ & $(0.135)$ & $(0.863)$ & $(0.385)$ & $(0.367)$ & $(0.274)$ & $(0.619)$ & $(0.022)$ \\
\hline \multirow[t]{2}{*}{$\mathrm{LS}_{\mathrm{W}}$} & 0.057 & 0.192 & -0.027 & 0.043 & 0.054 & 0.007 & 0.053 & 0.063 \\
\hline & $(0.641)$ & $(0.112)$ & $(0.822)$ & $(0.723)$ & $(0.660)$ & $(0.951)$ & $(0.665)$ & $(0.602)$ \\
\hline \multirow[t]{2}{*}{$\mathrm{DS}_{\mathrm{W}}$} & -0.171 & -0.132 & 0.027 & 0.007 & 0.059 & -0.005 & -0.167 & 0.125 \\
\hline & $(0.157)$ & $(0.276)$ & $(0.822)$ & $(0.953)$ & $(0.628)$ & $(0.967)$ & $(0.166)$ & $(0.304)$ \\
\hline \multirow[t]{2}{*}{$\mathrm{TST}_{\mathrm{W}}$} & -0.020 & -0.137 & -0.016 & -0.117 & $-0.267^{*}$ & -0.021 & 0.214 & $-0.528^{*}$ \\
\hline & $(0.872)$ & $(0.258)$ & $(0.893)$ & $(0.334)$ & $(0.026)$ & $(0.866)$ & $(0.075)$ & $(<0.001)$ \\
\hline \multirow[t]{2}{*}{$\mathrm{SO}_{\mathrm{F}}$} & $-0.353^{*}$ & 0.173 & 0.203 & $0.252^{*}$ & $0.458^{*}$ & 0.200 & -0.147 & $0.499^{*}$ \\
\hline & $(0.003)$ & $(0.152)$ & $(0.091)$ & $(0.035)$ & $(<0.001)$ & $(0.097)$ & $(0.233)$ & $<0.001$ \\
\hline \multirow[t]{2}{*}{$\mathrm{REMS}_{\mathrm{F}}$} & -0.024 & -0.089 & -0.091 & -0.011 & -0.050 & -0.147 & 0.035 & $-0.371^{*}$ \\
\hline & $(0.841)$ & $(0.462)$ & $(0.454)$ & $(0.925)$ & $(0.679)$ & $(0.223)$ & $(0.774)$ & $(0.002)$ \\
\hline \multirow[t]{2}{*}{$\mathrm{LS}_{\mathrm{F}}$} & 0.118 & 0.092 & 0.143 & -0.084 & -0.038 & 0.024 & 0.083 & 0.146 \\
\hline & $(0.331)$ & $(0.455)$ & $(0.239)$ & $(0.491)$ & $(0.757)$ & $(0.843)$ & $(0.493)$ & $(0.228)$ \\
\hline \multirow[t]{2}{*}{$\mathrm{DS}_{\mathrm{F}}$} & -0.250 & 0.016 & -0.076 & 0.216 & 0.193 & 0.072 & -0.118 & 0.164 \\
\hline & $(0.037)$ & $(0.898)$ & $(0.531)$ & $(0.073)$ & $(0.110)$ & $(0.554)$ & $(0.332)$ & $(0.175)$ \\
\hline \multirow[t]{2}{*}{$\mathrm{TST}_{\mathrm{F}}$} & 0.037 & -0.155 & -0.095 & $-0.287^{*}$ & $-0.420^{*}$ & -0.218 & 0.102 & $-0.432^{*}$ \\
\hline & $(0.764)$ & $(0.201)$ & $(0.434)$ & $(0.016)$ & $(<0.001)$ & $(0.069)$ & (0.399) & $(<0.001)$ \\
\hline \multirow[t]{2}{*}{ SJL } & $-0.326^{*}$ & 0.018 & 0.143 & 0.169 & 0.214 & $0.259^{*}$ & -0.001 & $0.281^{*}$ \\
\hline & $(0.006)$ & $(0.884)$ & $(0.239)$ & $(0.161)$ & $(0.076)$ & $(0.030)$ & $(0.991)$ & $(0.018)$ \\
\hline Chronotype & $-0.423^{*}$ & 0.160 & 0.198 & 0.222 & $0.394^{*}$ & 0.169 & -0.113 & $0.411^{*}$ \\
\hline (MSFsc) & $(<0.001)$ & $(0.185)$ & $(0.100)$ & $(0.065)$ & $(0.001)$ & $(0.161)$ & $(0.350)$ & $(<0.001)$ \\
\hline
\end{tabular}

Data are presented as rho ( $p$-value). ${ }^{*} p<0.05$. ESS, Epworth sleepiness scale; ISI, insomnia severity index; PSQI, Pittsburgh sleep quality index; FSS, fatigue severity scale; FIRST, Ford insomnia response to stress test; BPS, bedtime procrastination scale; $\mathrm{w}_{\text {, workdays; }}$, freedays; SO, sleep onset; REMS, REM sleep; LS, light sleep; DS, deep sleep; TST, total sleep time; SJL, social jetlag; MSFsc, mid-sleep time on free days corrected for sleep debt accumulated over the work week

는데, 이는 저녁형이 수면의 질이 낮고 우울감이 높다는 선 행연구와 유사한 결과이다. ${ }^{25}$ 본 연구대상자 중 일주기유형 $(=\mathrm{MSFsc})$ 이 4 시 이후인 경우가 전체 대상자 중 $35.6 \%$ 였는 데, 아침 출근 시간을 고려하면 하루 6시간 수면을 취한다고 하더라도 충분한 수면을 취하기 어려운 시간이다. 따라서 적 절한 수면을 보장하기 위해서는 일주기유형을 전진시키기 위한 노력이 필요한데, 이를 위해 기상 후 광치료나 운동도 추천된다. ${ }^{26,27}$ 무엇보다 수면의 중요성을 깨닫고 일찍 취침을 하게 하는 교육이 필요할 것으로 보인다.

한편 의사직과 간호직 대상자가 매우 적어 해석에 제한점 은 있으나, 직군별 일반적 특성 및 수면 패턴을 비교한 결과, 의사직의 근무시간이 다른 직군보다 2시간 정도 더 길었고,
근무일의 수면 패턴은 차이가 없으나 휴일의 수면시간대가 가장 뒤로 지연되는 성향을 보였다. 그럼에도 주관적인 수면 관련 설문 점수는 다른 직군에 비해 차이가 없거나 오히려 양호한 성향을 보여 수면시간이 수면의 질이나 수면 불편감 을 설명하지는 않는 것으로 보였다. 의사, 간호사 및 행정직 을 포함한 이란대학병원 직원 925명을 대상으로 PSQI로 수 면의 질을 조사한 연구에서 직군별 수면의 질은 차이가 없었 고, 나이가 많을수록, 주관적 건강상태를 나쁘게 평가할수록 수면의 질이 떨어진다고 보고하였다. ${ }^{28}$ 이러한 선행연구를 고려한다면 비록 통계적 차이는 없었지만 의사직이 휴일의 수면 시간대가 가장 뒤로 지연되어 사회적 시차가 크고, BPS 점수가 더 높았다. 이러한 경향성에도 불구하고 의사직이 수 
Table 4. Sleep parameters by Gallaxy Watch3 for 4 weeks according to job $(n=70)$

\begin{tabular}{|c|c|c|c|c|c|c|}
\hline Variables & $\begin{array}{l}\mathrm{MD} \\
(\mathrm{n}=5)\end{array}$ & $\begin{array}{l}\text { Nurse } \\
(\mathrm{n}=7)\end{array}$ & $\begin{array}{c}\text { Technician } \\
(\mathrm{n}=19)\end{array}$ & $\begin{array}{l}\text { Administrator } \\
(\mathrm{n}=22)\end{array}$ & $\begin{array}{c}\mathrm{RC} \\
(\mathrm{n}=17)\end{array}$ & $p$ \\
\hline Age, yr & $30.80 \pm 3.19$ & $40.29 \pm 5.12$ & $37.79 \pm 7.20$ & $34.73 \pm 9.35$ & $34.00 \pm 7.05$ & 0.181 \\
\hline Male, n (\%) & $2(40.0)$ & 0 & $12(63.2)$ & $9(40.9)$ & $9(52.9)$ & 0.051 \\
\hline BMI & $20.39 \pm 1.28$ & $22.79 \pm 3.96$ & $23.74 \pm 2.91$ & $23.89 \pm 3.25$ & $24.46 \pm 3.45$ & 0.065 \\
\hline Work-hour, hr & $11.10 \pm 1.08$ & $9.14 \pm 0.38$ & $9.14 \pm 0.59$ & $9.03 \pm 1.15$ & $9.15 \pm 0.68$ & $<0.001$ \\
\hline Start, clock hr & $7.50 \pm 0.35$ & $7.86 \pm 0.38$ & $7.94 \pm 0.16$ & $7.95 \pm 0.16$ & $8.15 \pm 0.39$ & 0.011 \\
\hline Finish, clock hr & $18.60 \pm 0.89$ & $17.00 \pm 0.58$ & $17.08 \pm 0.49$ & $16.98 \pm 0.77$ & $17.29 \pm 0.77$ & 0.002 \\
\hline ESS & $7.20 \pm 3.49$ & $8.00 \pm 3.70$ & $7.32 \pm 3.53$ & $8.91 \pm 4.05$ & $8.41 \pm 3.28$ & 0.766 \\
\hline ISI & $2.6 \pm 1.82$ & $4.7 \pm 2.43$ & $5.0 \pm 3.71$ & $7.18 \pm 4.33$ & $7.65 \pm 3.16$ & 0.014 \\
\hline PSQI & $3.40 \pm 1.82$ & $5.29 \pm 2.14$ & $4.11 \pm 2.03$ & $4.82 \pm 2.22$ & $6.00 \pm 1.84$ & 0.035 \\
\hline FSS & $26.20 \pm 6.06$ & $35.57 \pm 14.18$ & $25.68 \pm 8.31$ & $26.91 \pm 8.42$ & $32.59 \pm 9.19$ & 0.225 \\
\hline FIRST & $14.00 \pm 3.00$ & $25.00 \pm 7.14$ & $16.26 \pm 4.59$ & $19.27 \pm 7.50$ & $18.82 \pm 6.82$ & 0.061 \\
\hline BPS & $26.40 \pm 9.84$ & $19.86 \pm 5.84$ & $21.42 \pm 6.38$ & $20.77 \pm 8.45$ & $24.71 \pm 6.11$ & 0.350 \\
\hline $\mathrm{SO}_{\mathrm{w}}$, clock hr & $0.60 \pm 1.42$ & $23.25 \pm 0.82$ & $23.74 \pm 0.88$ & $23.64 \pm 0.92$ & $0.26 \pm 0.78$ & 0.054 \\
\hline $\mathrm{SE}_{\mathrm{W}}$, clock hr & $6.80 \pm 0.57$ & $6.39 \pm 0.30$ & $6.42 \pm 0.56$ & $6.37 \pm 0.74$ & $6.64 \pm 0.71$ & 0.469 \\
\hline $\mathrm{SD}_{\mathrm{W}}, \mathrm{hr}$ & $6.20 \pm 1.46$ & $7.14 \pm 0.80$ & $6.68 \pm 0.77$ & $6.73 \pm 0.97$ & $6.38 \pm 0.62$ & 0.202 \\
\hline $\mathrm{WASO}_{\mathrm{W}}, \%$ & $13.68 \pm 3.55$ & $10.20 \pm 1.75$ & $13.73 \pm 4.85$ & $12.24 \pm 3.16$ & $12.48 \pm 2.74$ & 0.383 \\
\hline $\mathrm{TST}_{\mathrm{W}}, \mathrm{hr}$ & $5.27 \pm 1.24$ & $6.34 \pm 0.58$ & $5.68 \pm 0.56$ & $5.85 \pm 0.79$ & $5.57 \pm 0.62$ & 0.062 \\
\hline $\mathrm{SO}_{\mathrm{F}}$, clock hr & $1.44 \pm 2.27$ & $23.53 \pm 0.97$ & $0.07 \pm 0.96$ & $23.99 \pm 0.99$ & $0.99 \pm 1.19$ & 0.020 \\
\hline $\mathrm{SE}_{\mathrm{F}}$, clock hr & $8.05 \pm 1.16$ & $7.00 \pm 0.56$ & $6.88 \pm 0.78$ & $6.95 \pm 0.98$ & $7.63 \pm 1.14$ & 0.043 \\
\hline $\mathrm{SD}_{\mathrm{F}}, \mathrm{h}$ & $6.62 \pm 1.96$ & $7.47 \pm 1.08$ & $6.81 \pm 0.85$ & $6.96 \pm 0.84$ & $6.64 \pm 1.09$ & 0.295 \\
\hline $\mathrm{WASO}_{\mathrm{F}}, \%$ & $12.86 \pm 4.63$ & $10.60 \pm 2.90$ & $14.93 \pm 5.24$ & $13.40 \pm 2.90$ & $13.93 \pm 2.96$ & 0.136 \\
\hline $\mathrm{TST}_{\mathrm{F}}, \mathrm{hr}$ & $5.68 \pm 1.18$ & $6.65 \pm 0.91$ & $5.86 \pm 0.72$ & $6.00 \pm 0.75$ & $5.64 \pm 0.93$ & 0.148 \\
\hline Social jetlag, hr & $1.04 \pm 0.77$ & $0.44 \pm 0.50$ & $0.40 \pm 0.46$ & $0.46 \pm 0.55$ & $0.86 \pm 0.75$ & 0.179 \\
\hline MSW, clock hr & $3.70 \pm 0.80$ & $2.82 \pm 0.47$ & $3.08 \pm 0.63$ & $3.01 \pm 0.68$ & $3.45 \pm 0.68$ & 0.077 \\
\hline MSF, clock hr & $4.75 \pm 1.48$ & $3.26 \pm 0.58$ & $3.48 \pm 0.89$ & $3.47 \pm 0.89$ & $4.31 \pm 1.03$ & 0.019 \\
\hline MSFsc, clock hr & $4.57 \pm 1.56$ & $3.11 \pm 0.64$ & $3.36 \pm 0.78$ & $3.33 \pm 0.93$ & $4.15 \pm 1.50$ & 0.035 \\
\hline
\end{tabular}

Data are presented as mean \pm standard deviation. MD, medical doctor; RC, research coordinator; ESS, Epworth sleepiness scale; ISI, insomnia severity index; PSQI, Pittsburgh sleep quality index; FSS, fatigue severity scale; FIRST, Ford insomnia response to stress test; BPS, bedtime procrastination scale; $w$, workdays; $\mathrm{F}$, freedays; SO, sleep onset; SE, sleep end; SD, sleep duration; WASO, wakefulness after sleep onset; TST, total sleep time; MSW, mid-sleep time on workdays; MSF, mid-sleep time on freedays; MSFsc, mid-sleep time on freedays corrected for sleep debt accumulated over the work week

면의 질이 더 좋다고 보고한 것은 아마도 나이가 적어서 신 체적 회복력이 좋아 수면의 질을 좋게 평가했을 가능성이 있 다. 향후 직군별 대상자 수를 충분히 확보하여 직군간의 비 교를 해 볼 필요가 있겠다.

이상을 종합해서 볼 때, 본 연구대상인 대학병원 상근자들 의 수면시간은 일반인에 비해 다소 짧고, 사회적 시차는 크 지 않으나 일주기유형은 지연된 양상을 보이는 경우가 많았 다. 병원 근로자의 수면부족은 단순히 개인의 건강에 미치는 영향 외에도 집중력을 떨어뜨려 병원내 사고 위험성 증가에 도 영향을 줄 수 있으므로, 주관적 수면의 질을 개선하고, 수 면시간을 증가시키기 위해서는 취침시간 지연행동을 줄이는 적극적인 중재가 필요하겠다. 또한 직종에 따라서 수면 패턴,
수면부족 정도가 차이가 있을 수 있으므로 직종간 수면 패턴 을 비교하는 연구도 필요하다.

본 연구 결과의 제한점은, 야간 시간대의 수면만 평가하였 기에 낮잠이 가능한 휴일의 수면시간이 과소 평가되었을 가 능성이 있다는 것이다. 이러한 제한점에도 불구하고, 웨어러 블 디바이스인 스마트워치를 이용해서 평소 일상생활을 유 지한 채 4주 이상의 수면을 측정해서 병원에 근무하는 상근 보건직 근로자의 수면패턴을 파악했다는 점에서 연구의 의 의가 있다.

\section{Conflicts of Interest}

The authors have no potential conflicts of interest to disclose. 


\section{ORCID iDs}

Su Jung Choi Hyunjin Jo

Dongyeop Kim

Eun Yeon Joo https://orcid.org/0000-0003-2171-7441 https://orcid.org/0000-0001-9563-1849 https://orcid.org/0000-0001-6045-0693 https://orcid.org/0000-0003-1233-959X

\section{Author Contributions}

Conceptualization: Su Jung Choi, Eun Yeon Joo. Data curation: Hyunjin Jo, Dongyeop Kim. Formal analysis: Su Jung Choi, Eun Yeon Joo. Investigation: Su Jung Choi, Hyunjin Jo. Methodology: Su Jung Choi, Dongyeop Kim. Supervision: Eun Yeon Joo. Visualization: Su Jung Choi. Writingoriginal draft: Su Jung Choi. Writing_-review \& editing: all authors.

\section{Funding Statement}

This research was supported by Samsung Medical Center Grant (OTC1190671).

\section{REFERENCES}

1. Weaver MD, Vetter C, Rajaratnam SMW, et al. Sleep disorders, depression and anxiety are associated with adverse safety outcomes in healthcare workers: a prospective cohort study. J Sleep Res 2018;27:e12722. https://doi.org/10.1111/jsr.12722.

2. Yi YH, Choi SJ. Association of sleep characteristics with medication errors for shift work nurses in intensive care units. J Korean Acad Fundam Nurs 2014;21:403-412. https://doi.org/10.7739/jkafn.2014.21.4.403.

3. Chae MJ, Choi SJ. Comparison of shift satisfaction, sleep, fatigue, quality of life, and patient safety incidents between two-shift and threeshift intensive care unit nurses. J Korean Crit Care Nurs 2020;13:1-11. https://doi.org/10.34250/jkccn.2020.13.2.1.

4. Baek JH, Choi-Kwon S. Sleep patterns, alertness and fatigue of shift nurses according to circadian types. J Korean Biol Nurs Sci 2017;19:198205. https://doi.org/10.7586/jkbns.2017.19.3.198.

5. Ganesan S, Magee M, Stone JE, et al. The impact of shift work on sleep, alertness and performance in healthcare workers. Sci Rep 2019;9:4635. https://doi.org/10.1038/s41598-019-40914-x.

6. Korsiak J, Tranmer J, Leung M, Borghese MM, Aronson KJ. Actigraph measures of sleep among female hospital employees working day or alternating day and night shifts. J Sleep Res 2018;27:e12579. https://doi. org/10.1111/jsr.12579.

7. Hulsegge G, Loef B, van Kerkhof LW, Roenneberg T, van der Beek AJ, Proper KI. Shift work, sleep disturbances and social jetlag in healthcare workers. J Sleep Res 2019;28:e12802. https://doi.org/10.1111/jsr.12802.

8. Cho S. A study on the relationship of job stressors and lifestyle behaviors to psychosocial wellbeing status among hospital workers [master's thesis]. Seoul: Yonsei University, 2004. 85p.

9. Walch O, Huang Y, Forger D, Goldstein C. Sleep stage prediction with raw acceleration and photoplethysmography heart rate data derived from a consumer wearable device. Sleep 2019;42:zsz180. https://doi. org/10.1093/sleep/zsz180.

10. Roenneberg T, Wirz-Justice A, Merrow M. Life between clocks: daily temporal patterns of human chronotypes. J Biol Rhythms 2003;18:8090. https://doi.org/10.1177/0748730402239679.
11. Cho YW, Song ML, Morin CM. Validation of a Korean version of the insomnia severity index. J Clin Neurol 2014;10:210-215. https://doi. org/10.3988/jen.2014.10.3.210.

12. Cho YW, Lee JH, Son HK, Lee SH, Shin C, Johns MW. The reliability and validity of the Korean version of the Epworth sleepiness scale. Sleep Breath 2011;15:377-384. https://doi.org/10.1007/s11325-010-0343-6.

13. Sohn SI, Kim DH, Lee MY, Cho YW. The reliability and validity of the Korean version of the Pittsburgh Sleep Quality Index. Sleep Breath 2012;16:803-812. https://doi.org/10.1007/s11325-011-0579-9.

14. Lee JH, Jeong HS, Lim SM, et al. Reliability and validity of the fatigue severity scale among university student in South Korea. Korean J Biol Psychiatry 2013;20:6-11.

15. Chang J, Suh S. Validation of the Korean ford insomnia response to stress test questionnaire. Sleep Med Res 2018;9:92-96. https://doi.org/10.17241/ smr.2018.00304.

16. An H, Chung SJ, Suh S. Validation of the Korean bedtime procrastination scale in young adults. J Sleep Med 2019;16:41-47. https://doi. org/10.13078/jsm.19030.

17. Ministry of Health and Welfare. Korea Centers for Disease Control and Prevention. Korea health statistics 2016: Korea national health and nutrition examination survey (KNHANES VII-1). Sejong: Ministry of Health and Welfare, 2017.

18. Chung SJ, An H, Suh S. What do people do before going to bed? A study of bedtime procrastination using time use surveys. Sleep 2020; 43:zsz267. https://doi.org/10.1093/sleep/zsz267.

19. Geng Y, Gu J, Wang J, Zhang R. Smartphone addiction and depression, anxiety: the role of bedtime procrastination and self-control. J Affect Disord 2021;293:415-421. https://doi.org/10.1016/j.jad.2021.06.062.

20. Roenneberg T, Pilz LK, Zerbini G, Winnebeck EC. Chronotype and social jetlag: a (self-) critical review. Biology (Basel) 2019;8:54. https:// doi.org/10.3390/biology8030054.

21. Wittmann M, Dinich J, Merrow M, Roenneberg T. Social jetlag: misalignment of biological and social time. Chronobiol Int 2006;23:497-509. https://doi.org/10.1080/07420520500545979.

22. Jankowski KS. Social jet lag: sleep-corrected formula. Chronobiol Int 2017;34:531-535. https://doi.org/10.1080/07420528.2017.1299162.

23. Åkerstedt T, Ghilotti F, Grotta A, et al. Sleep duration and mortality Does weekend sleep matter? J Sleep Res 2019;28:e12712. https://doi. org/10.1111/jsr.12712.

24. Fischer D, Lombardi DA, Marucci-Wellman H, Roenneberg T. Chronotypes in the US - Influence of age and sex. PLoS One 2017;12:e178782. https://doi.org/10.1371/journal.pone.0178782.

25. Horne CM, Watts AL, Norbury R. The influence of subjective sleep quality on the association between eveningness and depressive symptoms. Biol Rhythm Res 2019;50:534-542. https://doi.org/10.1080/09291 016.2018.1474576.

26. Figueiro MG, Plitnick B, Rea MS. The effects of chronotype, sleep schedule and light/dark pattern exposures on circadian phase. Sleep Med 2014;15:1554-1564. https://doi.org/10.1016/j.sleep.2014.07.009.

27. Thomas JM, Kern PA, Bush HM, et al. Circadian rhythm phase shifts caused by timed exercise vary with chronotype. JCI Insight 2020;5: e134270. https://doi.org/10.1172/jci.insight.134270.

28. Ghalichi L, Pournik O, Ghaffari M, Vingard E. Sleep quality among health care workers. Arch Iran Med 2013;16:100-103. 